\title{
Assortative Mating for Personality Traits, Educational Level, Religious Affiliation, Height, Weight, and Body Mass Index in Parents of a Korean Twin Sample
}

\author{
Yoon-Mi Hur \\ Graduate School of Education, Hansung University, Seoul, Korea
}

\begin{abstract}
The degree of assortative mating for psychological and physical traits in Asian societies is relatively unknown. The present study examined assortative mating for educational level, personality traits, religious affiliation, height, weight, and body mass index in a Korean sample. Age-adjusted spouse correlations were high for educational level $(r=.63)$ and religious affiliation ( $r=.67$ ), modest for most personality traits ( $r \mathrm{~s}=$ -.01 to .26$)$, and trivial for height $(r=.04)$, weight $(r=.05)$, and body mass index $(r=.11)$. These results were remarkably similar to those found from the western samples. Implications of the present findings in behavior genetic studies and human mating patterns were briefly discussed.
\end{abstract}

Assortative mating is the tendency for spouses to resemble each other more than expected by chance. Assortative mating can affect the genetic structure of a population by increasing genetic variance and covariance (Cavalli-Sforza \& Bodmer, 1971; Crow \& Felsenstein, 1982) and natural selection (Eckland, 1982). Behavior geneticists have long been interested in assortative mating because it influences heritability estimates in twin and family studies by increasing genetic resemblance between first-degree relatives. Assortative mating has been documented for a variety of variables. In general, age, race, religion, and ethnic background show the strongest assortment. These are followed by education (spouse $r=0.50-0.65$ ) and attitudes (spouse $r=0.50-.60$ ) and then by mental abilities (spouse $r=$ $0.30-0.40$ ), socioeconomic status (spouse $r=0.30$ ), height, weight, and body mass index (spouse $r=0-0.30$ ), and personality traits (spouse $r=0-0.25$ ). Reviews of studies of assortative mating can be found in Vandenberg (1972), Jensen (1978), Spuhler (1982), Grilo and Pogue-Geile (1991), and Hur (2001).

The vast majority of studies of assortative mating have been conducted using couples from western societies and, therefore, the degree of assortment in non-western cultures is relatively unknown. The purpose of the present study is to examine degrees of assortative mating in Korean couples on personality traits, educational level, religious affiliation, height, weight, and body mass index (BMI). In Asian societies arranged marriages are still common, which may cause degrees of spouse resemblance in Asian societies to be different from those found in the western world. Because the number of twin and family studies using Asian populations is increasing, the present data provide important information for understanding genetic and environmental influences on psychological and physical traits estimated from Asian populations.

\section{Method \\ Sample}

The sample consists of parents of the elementary school twins who participated in the Seoul Twin Family Study (STFS). The STFS is a large, longitudinal twin family study of genetic and environmental influences on the development of cognitive abilities and other psychological traits in children and adolescents in Seoul, Korea. Twins and their parents in the STFS were ascertained systematically from all private and public schools in Seoul. The study design and recruitment procedures of the STFS sample are described in detail elsewhere (Hur, 2002). The subjects for the present analysis include 501 parents of the twins who responded to the mail survey of the STFS in year $2002 .{ }^{1}$ The couples ranged in age from 27 to 70 years. The mean ages were $41.4(S D=4.6)$ and $38.4(S D=4.2)$ years for husbands and wives, respectively. The average years of formal education were 13.6 years for fathers and 13.1 years for mothers. These figures were only slightly higher than the average years of formal education for males (12.6 years) and females (11.5 years) aged between 30 and 49 years as of year 2000 in Korea (Korea National Statistical Office, 2002), indicating that the present sample is fairly representative of Korean adults of the corresponding age group in terms of educational attainment .

\section{Measures}

Personality. To assess personality traits of the couples, a shortened version of the Multidimensional Personality

Address for correspondence: Yoon-Mi Hur, Graduate School of Education, Hansung University, 389 Samsun-dong 2-ga, Sungbuk-gu, Seoul 136-792, Korea.Email: maryhur@hananet.net 
Questionnaire (S-MPQ) was used. The S-MPQ contains 34 items assessing a broad range of individual differences in affective and behavioral style. The 34 items have a 4point rating scale (strongly agree to strongly disagree). Two bilinguals translated the English version of the 34 items into Korean. The 34 items of the S-MPQ produce 10 scales (i.e., Stress Reaction, Alienation, Aggression, Wellbeing, Social Potency, Social Closeness, Achievement, Control, Harm Avoidance, and Traditionalism), which are described in Table 1 (the Absorption scale was not used in the present analyses). The 10 personality traits have been studied intensively in previous studies (e.g., Tellegen et al., 1988; Waller \& Shaver, 1994). Alpha reliabilities for the 10 scales of the S-MPQ in the present sample ranged from .43 to .70 with a mean of .56.

\section{Table 1}

Description of the 10 Scales of the Short Version of the Multidimensional Personality Questionnaire

\begin{tabular}{ll}
\hline Primary scale & Self-descriptions of High Scorers \\
\hline Wellbeing & Happy, cheerful, satisfied, active \\
Social Potency & Persuasive, decisive, enjoys taking charge \\
Achievement & Works hard, persists, pursues perfection \\
Social Closeness & Sociable, warm, likes people \\
Stress Reaction & Nervous, easily upset, worries a lot \\
Alienation & Feels mistreated, exploited, \\
& victim of bad luck \\
Aggression & Physically aggressive, vindictive \\
Control & Orderly, neat, cautious, careful \\
Harm Avoidance & Avoids risks, dangers, thrills, \\
and adventures \\
Traditionalism
\end{tabular}

Educational level. In addition to the S-MPQ, the couples completed an extensive biographical questionnaire that included questions on educational level, religious affiliation, height, weight, and so forth. The rating scale of the educational level ranged from 1 to 6 , where 1 = graduated from an elementary school (i.e., 6 years of formal education), 2 = graduated from a middle school (i.e., 9 years of formal education), 3 = graduated from a high school (i.e., 12 years of formal education), 4 = graduated from a junior college (i.e., 14 years of formal education), 5 = graduated from a college (i.e., 16 years of formal education), and $6=$ postgraduate education (i.e., longer than 16 years of formal education).

Religious affiliation. Religious affiliation was classified into five response categories: Protestant $=1$, Catholic $=2$, Buddhism $=3$, No religion $=4$, Others $=5$.

Height, weight, and body mass index. Height and weight were reported in centimeters and kilograms, respectively. BMI was calculated as weight in kilograms divided by height in meters squared.

\section{Results \\ Descriptive Statistics}

Table 2 presents the means and SDs for height, weight, BMI, level of education, and the 10 S-MPQ scales for husbands and wives.

To compare husbands and wives, paired-sample $t$ tests were conducted for height, weight, BMI, educational level, and the 10 personality scales. Husbands showed significantly higher scores than wives for height, weight, BMI, and educational level. Husbands were significantly higher than wives on four of the 10 personality scales (Wellbeing, Social Potency, Achievement, and Alienation) and lower on three of the 10 scales (Stress Reaction, Harm Avoidance, and Traditionalism).

Table 2

Means and SDs for Height, Weight, BMI, Educational Level, and 10 Personality Scales of the Short Version of the Multiple Personality Questionnaire

\begin{tabular}{|c|c|c|c|c|c|}
\hline \multirow[b]{2}{*}{ Variables } & \multirow[b]{2}{*}{$N$ couples } & \multicolumn{2}{|c|}{ Husbands } & \multicolumn{2}{|c|}{ Wives } \\
\hline & & Mean & $S D$ & Mean & $S D$ \\
\hline Height (meters) ${ }^{* *}$ & 462 & 1.71 & 4.85 & 1.60 & 4.29 \\
\hline Weight $(\mathrm{kg})^{* *}$ & 429 & 69.67 & 8.51 & 56.43 & 7.39 \\
\hline $\mathrm{BMI}^{* *}$ & 427 & 23.72 & 2.43 & 22.15 & 2.70 \\
\hline Educational level** & 461 & 3.88 & 1.21 & 3.44 & 1.06 \\
\hline \multicolumn{6}{|l|}{ Personality scales } \\
\hline Well-Being* & 501 & 9.04 & 1.32 & 8.86 & 1.32 \\
\hline Social Potency** & 497 & 8.07 & 1.55 & 7.67 & 1.53 \\
\hline Achievement ${ }^{* *}$ & 493 & 9.03 & 1.42 & 8.52 & 1.45 \\
\hline Social Closeness & 495 & 8.52 & 1.29 & 8.49 & 1.28 \\
\hline Stress Reaction** & 496 & 7.12 & 1.52 & 7.45 & 1.64 \\
\hline Alienation** & 494 & 5.93 & 1.40 & 5.62 & 1.39 \\
\hline Aggression & 497 & 5.77 & 1.32 & 5.80 & 1.34 \\
\hline Control & 495 & 8.44 & 1.42 & 8.43 & 1.38 \\
\hline Harm Avoidance ${ }^{* *}$ & 496 & 8.57 & 1.40 & 9.06 & 1.41 \\
\hline Traditionalism ${ }^{* *}$ & 493 & 12.14 & 1.48 & 12.44 & 1.58 \\
\hline
\end{tabular}

Note: $N$ varies because some subjects did not complete the questionnaires.

${ }^{*} p<.05,{ }^{* *} p<.01$ : two-tailed comparisons between husbands and wives. 


\section{Spouse Correlations}

Spouses are highly correlated for age so that spouse similarity for various traits can be influenced by age. In the present sample the spouse correlation for age was .74. Table 3 reports spouse correlations for height, weight, BMI, educational level, and the 10 personality scales. Those spouse correlations adjusted for age are also reported in Table 3 .

As indicated in Table 3, spouse correlations changed very little after removing age effects, indicating that age effects on spouse similarity are minimal for height, weight, BMI, educational level and personality traits. These results were consistent with previous studies of assortative marriage using Western samples (e.g., Mascie-Taylor \& Vandenberg, 1989; Price \& Vandenberg, 1980).

Spouse correlations for height, weight, and BMI were very small (age-adjusted $r=.04$ to .11 ) and mostly nonsignificant. Spouses were significantly correlated $(p<.05)$ on seven of the 10 personality scales. The magnitudes of the age-adjusted spouse correlations for the 10 personality scales, however, were generally modest. They ranged from -.01 to .26 , with a mean of .14 . The spouse correlation for

\section{Table 3}

Spouse Correlations for Height, Weight, BMI, Educational Level, and 10 Personality Scales of the Short Version of the Multiple Personality Questionnaire $(N=427-501)$

\begin{tabular}{lcc}
\hline Variables & $r$ & $r$ \\
& (unadjusted for age) & (adjusted for age) \\
\hline Height (meter) & .03 & .04 \\
Weight (Kg) & .03 & .05 \\
BMI.09 & $.11^{*}$ & \\
Educational level & $.67^{* *}$ & $.63^{* *}$ \\
Personality scales & & \\
Wellbeing & $.23^{* *}$ & $.24^{* *}$ \\
Social Potency & $.20^{* *}$ & $.20^{* *}$ \\
Achievement & $.13^{* *}$ & $.14^{* *}$ \\
Social Closeness & .06 & .07 \\
Stress Reaction & .02 & .01 \\
Alienation & $.23^{* *}$ & $.23^{* *}$ \\
Aggression & $.10^{*}$ & .09 \\
Control & $.00^{*}$ & .01 \\
Harm Avoidance & $.11^{*}$ & $.12^{*}$ \\
Traditionalism & $.26^{* *}$ & $.26^{* *}$ \\
\hline Note: ** $p<.01 * * 0.05$ & &
\end{tabular}

Table 4

Frequencies of Religious Affiliation for Husbands and Wives

\begin{tabular}{lrrrr}
\hline & \multicolumn{2}{c}{ Husbands } & \multicolumn{2}{c}{ Wives } \\
Affiliation & $N$ & $\%$ & $N$ & $\%$ \\
\hline Protestants & 107 & 24 & 141 & 32 \\
Catholic & 40 & 9 & 54 & 12 \\
Buddhism & 88 & 20 & 89 & 20 \\
Others & 2 & 1 & 1 & 1 \\
No religion & 205 & 46 & 157 & 36 \\
Total & 442 & $100 \%$ & 442 & $100 \%$
\end{tabular}

the educational level was very high: .63 after adjustment for age.

Table 4 reports the frequencies of the five response categories of religious affiliation for husbands and wives. Spearman's rho coefficient between husband and wives religious affiliation was .67 $(p<.001)$, suggesting that there is a significant association between husbands and wives for religious affiliation.

\section{Discussion}

The present study examined the degree of assortative mating for various traits in a sample of Korean couples. Age-adjusted spouse correlations were high for educational level $(r=.63)$, modest for most personality traits $\left(r_{s}=-.01\right.$ to .26), and negligible for height $(r=.04)$, weight $(r=.05)$, and BMI $(r=.11)$. Significant assortment was also found for religious affiliation (Spearman's rho $=.67$ ). Interestingly, these results are remarkably similar to those found from the Western samples.

It has been argued that assortative mating is very high in Korea. Johnson et al. (1976), for example, studied cognitive abilities in 209 Korean couples and found the spouse correlation for the unrotated first principal component of the 15 specific cognitive abilities to be .72 , a value much higher than those typically found in western samples. Johnson et al. (1976) attributed this extremely high spouse correlation for cognitive ability to the method of test administration (the subjects were tested as family units) and the practice of arranged marriages prevalent in Korean society. In the custom of arranged marriages, match makers often arrange the marriage of individuals of similar ability, parental social status, and family reputation.

Because cognitive ability data are not available for the present sample, a direct comparison between Johnson et al.'s study and the present one is not possible. Given the amount of assortment for educational level found in the present sample, however, it is very unlikely that the spouse correlation for cognitive ability is as high as .72 in the current Korean population. One plausible explanation for the discrepancy between Johnson et al.'s results and the present finding is that with an increase of free marriages in Korean society, assortment for traits related to social class, such as educational attainment or intelligence may have decreased over the years. The couples in Johnson et al.'s study were tested in 1973-1974 and were old enough then to have had children at least 14 years of age, whereas the majority of the couples in the present sample were in the late 30 s and early 40 s.

In conclusion, the present findings have two major implications. First, assortative mating may affect heritability estimates in Asian populations to the same degree as in Caucasian populations. Second, degrees of assortment for psychological and physical traits might be quite similar across most modern, industrialized societies.

\section{Endnotes}

1 Two couples were grandparents of the twins. 


\section{$\overline{\text { Acknowledgment }}$}

This work was supported by a Korea Research Foundation Grant (KRF-2001-041-C00548).

\section{References}

Crow, J. F., \& Felsenstein, J. (1982). The effect of assortative mating on the genetic composition of a population. Social Biology, 29, 22-35.

Cavalli-Sforza, L. L., \& Bodmer, W. F. (1971). The genetics of buman population. San Francisco: Freeman.

Eckland, B. K. (1982). Mate selection. Social Biology, 29, 7-21.

Grilo, C. M., \& Pogue-Geile, M. F. (1991). The nature of environmental influences on weight and obesity: A behavior genetic analysis. Psychological Bulletin, 110, 520-537.

Hur, Y-M. (2001). Assortative mating for psychological and physical traits. Korean Journal of Psychology, 20, 429-448.

Hur Y-M. (2002). Seoul Twin Family Study: Design, sampling, assessments, and future directions. Twin Research, 5, 389-393.

Jensen, A. R. (1978). Genetic and behavioral effects of nonrandom mating. In Human variation: Biopsychology of age, race, and sex. New York: Academic Press.
Johnson, R. C., Park, J., DeFries, J. C., McClearn, G. E., Mi, M. P., Rashad, M. N., et al. (1976). Assortative marriage for specific cognitive abilities in Korea. Social Biology, 23, 311-316.

Korean National Statistical Office. (2002). Population \& housing census report. In Social indicators in Korea. Seoul: Author.

Mascie-Taylor, C. G. N. (1989). Spouse similarity for IQ and personality and convergence. Behavior Genetics, 19, 223-227.

Price, R. A., \& Vandenberg, S. G. (1980). Spouse similarity in American and Swedish couples. Behavior Genetics, 10, 59-71.

Spuhler, J. N. (1982). Assortative mating with respect to physical characteristics. Social Biology, 29, 53-66.

Tellegen, A., Lykken, D. T., Bouchard, T. J., Jr., \& Wilcox, K. J. (1988). Personality similarity in twins reared apart and together. Journal of Personality and Social Psychology, 54, 1031-1039.

Vandenberg, S. G. (1972). Assortative mating, or who marries whom? Behavior Genetics, 2, 127-157.

Waller, N. G., \& Shaver, P. R. (1994). The importance of nongenetic influences on romantic love styles: A twin-family study. Psychological Science, 5, 268-274. 